\title{
KARAKTERISITIK FLOW PATERN PADA ALIRAN DUA FASE GAS-CAIRAN MELEWATI PIPA VERTIKAL
}

\author{
PRIYO HERU ADIWIBOWO \\ Jurusan Teknik Mesin, Fakultas Teknik Universitas Negeri Surabaya \\ E-mail: apriyoheru@gmail.com
}

\begin{abstract}
ABSTRAK
Aliran dua fase seringkali dijumpai dalam beberepa ilmu teknik dan fasilitas industri seperti plant tenaga uap konvensional, evaporator dan kondensor, reaktor nuklir tekanan air, berbagai indutri petrol, industri pemrosesan makanan dan bahan kimia. Dalam instalasi saluran pipa sistem tersebut yang kompleks, pipa vertikal akan sering dipakai untuk penghubung pipa. Pada penelitian ini bertujuan untuk mengetahui pengaruh penggunaan pipa vertikal terhadap karakteristik flow patern pada aliran dua fase gas-cairan. Penelitian yang dilakukan secara eksperimental mengunakan pipa transparan dengan diameter dalam $36 \mathrm{~mm}$ pada pipa vertikal serta air sebagai fluida kerja cairan dan udara sebagai fluida kerja gas. Variasi yang dilakukan adalah kecepatan superficial cairan antara dari 0,3-0,5 $\mathrm{m} / \mathrm{s}$ dan $\mathrm{p}$ adalah 0,05-0,2. Visualisasi flow patern pada pipa vertikal menggunakan kamera digital. Dari hasil penelitian dapat diperoleh kesimpulan bahwa aliran dua fase gas cairan yang melewati pipa vertikal terjadi perubahan karakterisitik flow patern yang dipengaruhi oleh kecepatan superficial cairan dan kualitas volumetrik gas. Pada setiap kecepatan superficial cairan untuk kualitas volumetrik gas menengah (medium) terjadi homogeneous bubbly flow dan dense bubbly flow untuk kisaran kualitas volumetrik gas yang tinggi.
\end{abstract}

Kata kunci: pipa vertikal, aliran dua fase gas-cairan, flow patern

\begin{abstract}
Multi-phase flows are widely encountered in several engineering and industrial facilities, such as conventional steam power plants, evaporators and condensers, pressurized-water nuclear reactors, a wide variety of petroleum industries, chemicals and food processing industries. Surely, in the complex pipeline installation of these systems, vertical pipe will be commonly used for pipe connection. The purpose of this work is to investigate the flow pattern of gas-liquid two phase in the vertical pipe. Experiments will be performed in a $36 \mathrm{~mm} I D$ acrylic pipe vertical. Superficial liquid velocities and volumetric gas quality will be varied 0.3-1,1 m/s and 0.05-0.2 respectively. Digital camera will be used for flow pattern visualization in the vertical pipe. It was observed that effect of vertical pipe onflow pattern formed cluster bubbly flow for low volumetric gas quality with high superficial liquid velocities. For superficial liquid velocities with medium volumetric gas quality formed homogeneous bubbly flow and high volumetric gas quality is dense bubbly flow.
\end{abstract}

Key words: gas-liquid two-phase flow, flow patterns, vertical pipe

\section{PENDAHULUAN}

Aliran dua fase adalah merupakan bagian dari aliran multi fase mempunyai fenomena yang sangat kompleks dibanding pada aliran satu fase di antaranya adalah interaksi antar fase, pengaruh deformasi permukaan dan pergerakan antar fluida, pengaruh ketidakseimbangan fase, perubahan pressure drop dan lain sebagainya. Pada aliran satu fase hanya ada pressure drop yang dipengaruhi oleh Reynold number yang merupakan fungsi dari viskositas, berat jenis fluida dan diameter pipa. Sedangkan pada aliran multiphase di dalam saluran tertutup (pipa) tidak hanya dipengaruhi oleh Reynold number tetapi fase-fase yang bercampur di dalamnya mempunyai pengaruh yang signifikan. sehingga akan terdapat banyak flow regime (flow pattern) yang terbentuk dalam saluran tersebut akibat interaksi antar fase fluida tersebut. Aliran yang mengalami perubahan flow pattern (flow regime) dapat menyebabkan pressure drop yang berubah-ubah pula atau berfluktuasi (Somchai,2005). Oleh karena itu saat ini yang menjadi ketertarikan dalam penelitian adalah informasi mengenai karakteristik flow patern pada aliran dua fase yang terjadi sepanjang aliran pipa vertikal.

Beberapa penelitian yang telah dilakukan yang berhubungan dengan pressure drop dan flow patern pada aliran dua fase pada pipa vertikal dan horizontal. Secara umum parameter-parameter yang diperhatikan di antaranya debit fluida cair dan gas, 
viskositas fluida, flow patern, tegangan geser antar fase dan konfigurasi pipa. Spedding (1998) meneliti tentang aliran dua fase vertikal air - udara dengan diameter dalam (ID) $0.026 \mathrm{~m}$. Data yang dihasilkan hanya pressure drop, belum menampilkan bentuk flow patern. Saisorn (2007) menemukan sebuah investigasi pada karakteristik-karekteristik aliran dua fase (flow pattern, void fraction dan pressure drop) dalam sebuah micro circular channel dengan diameter 0,53 mm. Bentuk-bentuk two-phase flow termasuk slug flow, throat-annular flow, churn flow dan annular-rivulet flow telah diobservasi. Eksperimeneksperimennya juga menunjukkan bahwa tidak ada perbedaan-perbedaan yang signifikan dalam data dari penggunaan udara atau gas nitrogen, dan air atau de-ionized water sebagai fluids aktif. Ini bisa jadi karena tidak ada perubahan properties fluid dan diameter pipa. Penelitiannya menginformasikan tentang flow patern, void fraction dan pressure drop tetapi pada diameter pipa sangat kecil. Karayiannis (2006) meneliti pengaruh dari diameter pipa untuk flow patern aliran dua fase vertikal. Dengan variasi diameter dalam (ID) yang digunakan yaitu: 1.10, 2.01, 2.88 and $4.26 \mathrm{~mm}$. Fluida kerja cairannya adalah R134a. Penelitiannya menginformasikan tentang flow patern dan pressure drop tetapi pada diameter pipa sangat kecil.

Dari banyak penelitian yang telah dilakukan dan dipublikasikan mengenai karakteristik-karakteristik aliran dua fase untuk mempelajari fenomena aliran dua fase flow patern, void fraction dan pressure drop telah dilakukan investigasi dengan membuat modelmodelnya dan korelasi yang telah dikembangkan untuk flow patern transisi, presure drop dan distribusi void fraction dalam pipa horisontal, vertikal dan miring dengan beragam dimensi. Tetapi dari banyak studi tentang aliran dua fase yang dijelaskan sebelumnya fenomena pengamatan secara visualisasi dan eksperimen karakteristik pada pipa vertikal tentang flow patern masih terbatas informasinya. Untuk penelitian ini dengan cara menambahkan ruang lingkup sebelumnya diharapkan dapat mengetahui bagaimana aliran dua fase pada pipa vertikal terhadap karakterisik flow patern. Dengan menggunakan air sebagai fluida kerja cairan dan udara sebagai fluida kerja gas. Sedangkan untuk melihat karakteristik flow patern dan visualisasi aliran dua fase gas cairan yang melewati pipa vertikal akan menggunakan kamera digital.

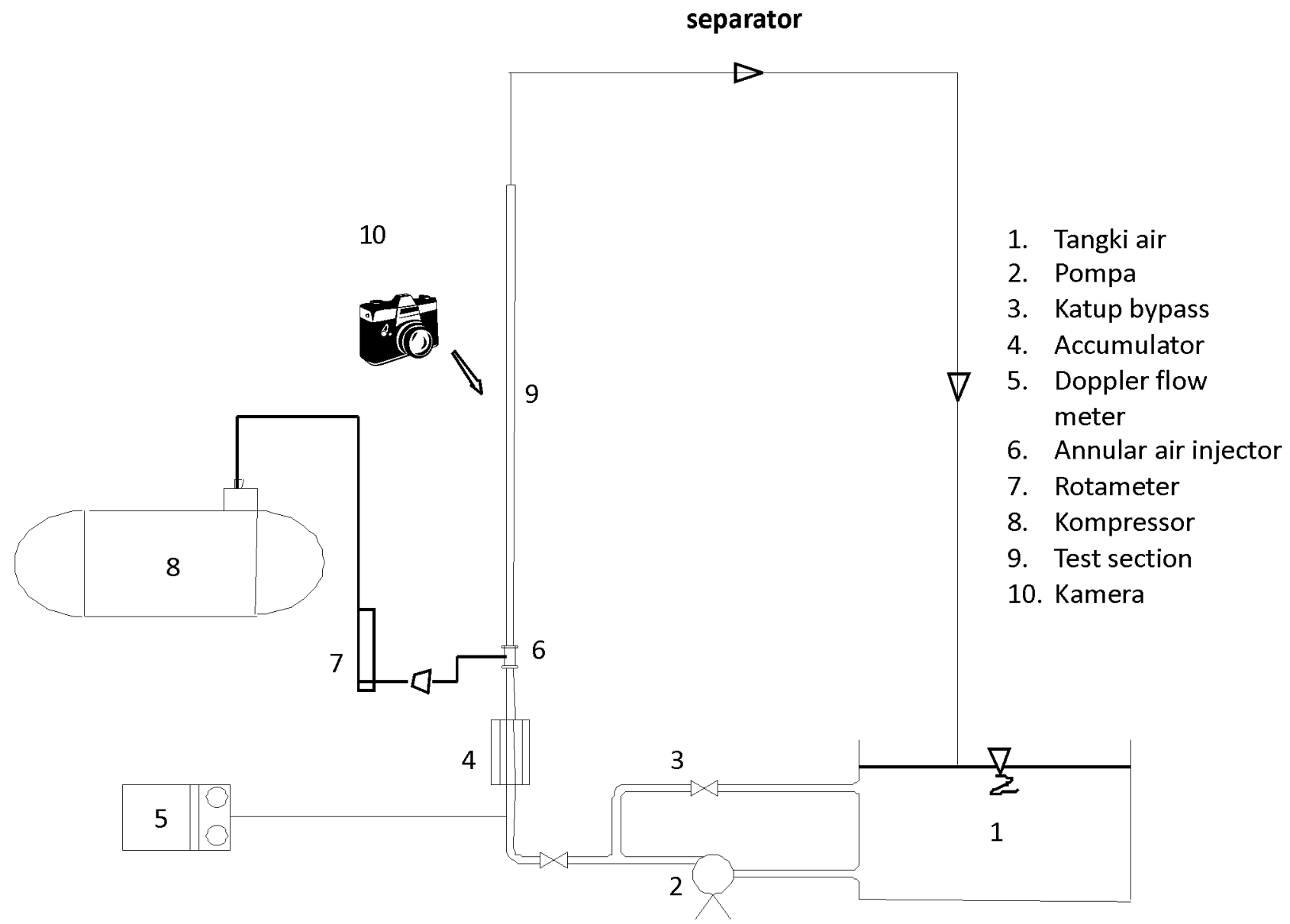

Gambar 1. Skema instalasi penelitian 


\section{METODE}

Dalam penelitian aliran dua fase secara eksperimen ini skema penelitiannya dapat dilihat pada gambar 1. Untuk melaksanakan eksperimen peralatan yang digunakan terdiri dari tangki air, pompa sentrifugal, sistem aliran, water accumulator, test section, gas-cairan separator dan gas supply system. Test section terbuat dari pipa akrelik dengan diameter dalam $36 \mathrm{~mm}$ dan panjang pipa vertikal adalah $2 \mathrm{~m}$.

Air dan udara akan bercampur dalam test section. Udara dari kompresor akan diinjeksikan ke test section melalui injektor udara yang berbentuk annular dengan 32 lubang dengan diameter dalam $710 \mu \mathrm{m}$. Laju alir cairan akan diukur menggunakan "Doppler" flow meter dan laju alir gas akan diukur dengan menggunakan rotameter tipe pelampung. Untuk mengetahui temperatur udara menggunakan termocouple yang terpasang pada outlet dari rotameter. Eksperimen akan dilakukan dengan ariasi kecepatan superficial cairan antara $0,3-1,1 \mathrm{~m} / \mathrm{s}$ dan kualitas volumetrik gas antara 0,05-0,2 diduga akan menghasilkan karakteristik flow patern yang berbeda pada pipa vertikal. Pengamatan visual dari bubbly flow dengan menggunakan kamera digital pada ketinggian $0,35 \mathrm{~m}$ di atas bubble injector.

Tabel 1. Properti fluida yang diambil dalam pengukuran pada temperatur rata-rata $30^{\circ} \mathrm{C}$.

\begin{tabular}{lcc}
\hline Fluida & Density, $\rho \mathbf{( k g} / \mathbf{m 3})$ & Viscosity, $\boldsymbol{\mu}(\mathbf{N} . \mathbf{s} / \mathbf{m} 2)$ \\
\hline air & 996 & $7.79 \times 10-4$ \\
udara & 1.17 & $1.86 \times 10-5$ \\
\hline
\end{tabular}

\section{HASIL DAN PEMBAHASAN}

\section{Karakteristik Flow Pattern pada Aliran Dua Fase}

Aliran dua fase merupakan bagian dari aliran multi-fase. Studi tentang aliran dua fase dapat kita perhatikan atas beberapa bagian, yaitu: wujud fase (gas-cair, cair-padat, dan padat-gas), arah aliran (searah ke atas, searah ke bawah, dan berlawanan arah), dan kedudukan saluran (mendatar, tegak atau miring). Aliran dua fase yang berbeda ini banyak dijumpai dalam kehidupan sehari-hari maupun prosesproses industri.

Aliran kantung ditandai oleh bentuk gelembung (bubble) gas yang relatif berukuran panjang dan hampir memenuhi penampang saluran aliran. Aliran kantung dapat terjadi apabila kecepatan aliran gas dan cairan terus ditingkatkan sehingga memungkinkan timbulnya gelembung. Apabila kecepatan cairan lebih

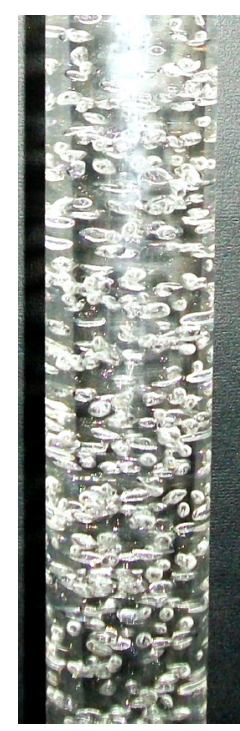

(a)

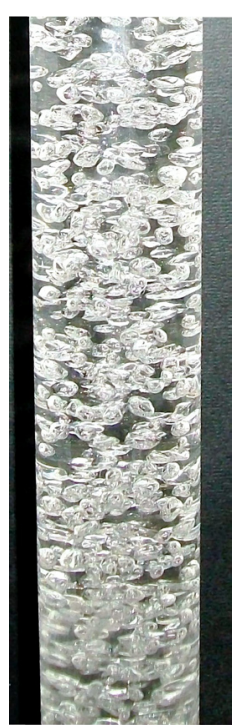

(b)
$\operatorname{Re}_{\mathrm{SL}}=13497, \beta=0,11 \quad \operatorname{Re}_{\mathrm{SL}}=13497, \beta=0,2$

Gambar 2. Visualisasi dari bubbly flow pada pipa uji vertikal dengan ketinggian $0,35 \mathrm{~m}$ di atas bubble injector untuk $\mathrm{Re}_{\mathrm{SL}}=13497\left(\mathrm{U}_{\mathrm{SL}}=\right.$ $0,3 \mathrm{~m} / \mathrm{s})$

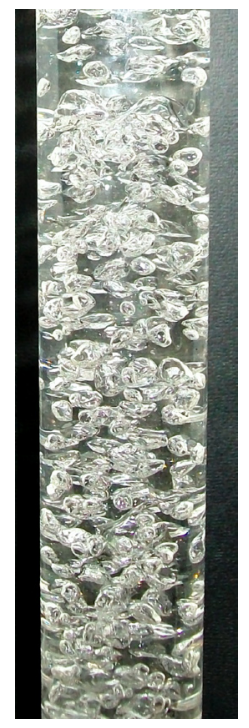

(a)

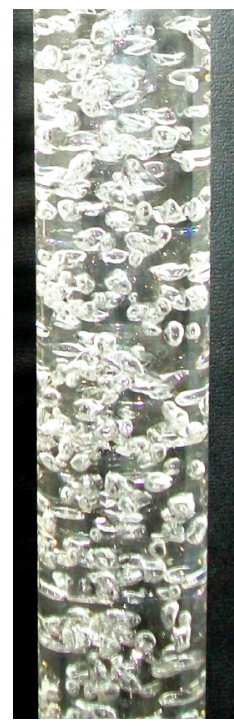

(b)

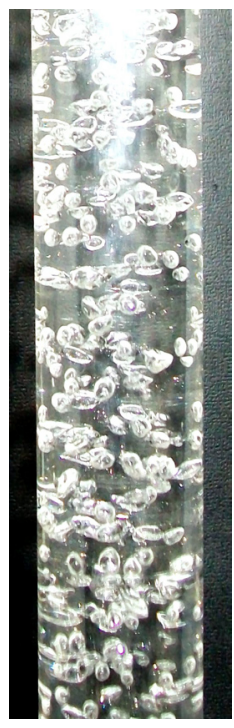

(b)
$\operatorname{Re}_{\mathrm{SL}}=22494, \beta=0,07 \operatorname{Re}_{\mathrm{SL}}=22494, \beta=0,11 \quad \operatorname{Re}_{\mathrm{SL}}=22494, \beta=0,2$

Gambar 3. Visualisasi dari bubbly flow pada pipa uji vertikal dengan ketinggian $0,35 \mathrm{~m}$ di atas bubble injector untuk $\mathrm{Re}_{\mathrm{SL}}=22494$ $\left(\mathrm{U}_{\mathrm{SL}}=0,5 \mathrm{~m} / \mathrm{s}\right)$

besar dari kecepatan gas, maka kantung udara yang telah terbentuk akan cepat pecah.

Dalam aliran gelembung (bubble flow) fase gas atau uap disebarkan sebagai gelembung yang mempunyai ciri tersendiri dalam fase cairan secara kontinu. Pada satu sisi gelembung bisa kecil dan berbentuk bulat 


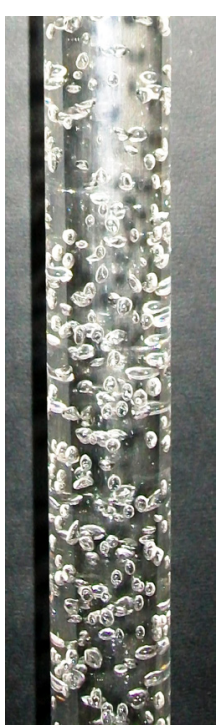

(a)

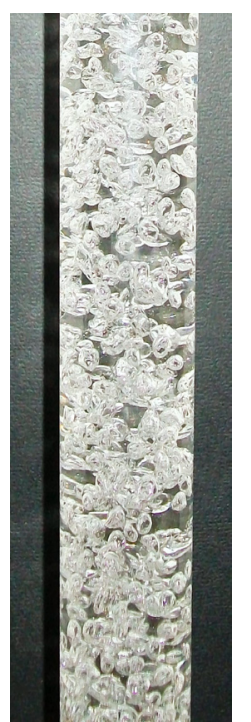

(b)

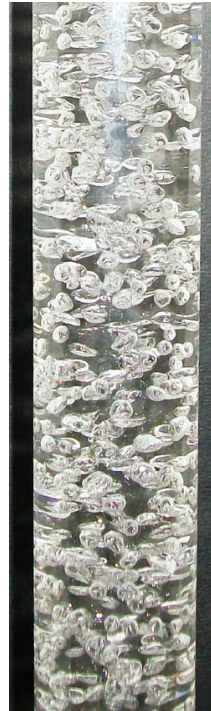

(c)

$\operatorname{Re}_{\mathrm{SL}}=31492, \beta=0,05 \quad \operatorname{Re}_{\mathrm{SL}}=31492, \beta=0,11 \quad \operatorname{Re}_{\mathrm{SL}}=31492, \beta=0,2$

Gambar 4. Visualisasi dari bubbly flow pada pipa uji vertikal dengan ketinggian $0,35 \mathrm{~m}$ di atas bubble injector untuk $\mathrm{Re}_{\mathrm{SL}}=31492\left(\mathrm{U}_{\mathrm{SL}}=\right.$ $0,7 \mathrm{~m} / \mathrm{s})$

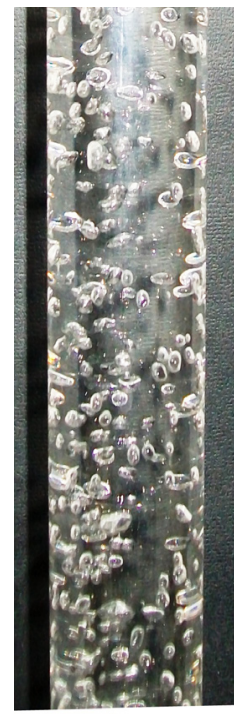

(a)

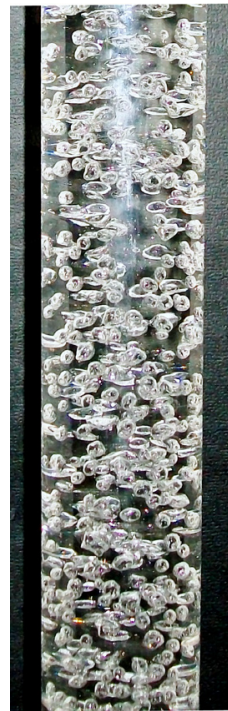

(b)

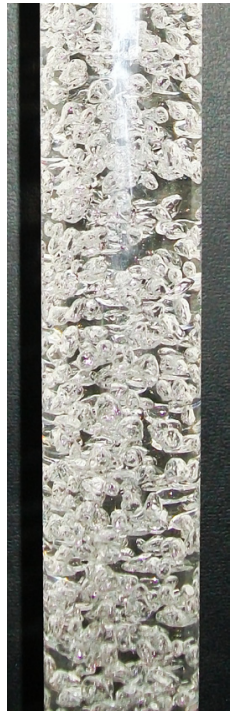

(c)

$\operatorname{Re}_{\mathrm{SL}}=40490, \beta=0,05 \operatorname{Re}_{\mathrm{SL}}=40490, \beta=0,11 \quad \operatorname{Re}_{\mathrm{SL}}=40490, \beta=0,2$

Gambar 5. Visualisasi dari bubbly flow pada pipa uji vertikal dengan ketinggian $0,35 \mathrm{~m}$ di atas bubble injector untuk $\mathrm{Re}_{\mathrm{SL}}=40490\left(\mathrm{U}_{\mathrm{SL}}=\right.$ $0,9 \mathrm{~m} / \mathrm{s})$

dan di sisi lain gelembung bisa besar dengan bentuk bulat dan datar. Dalam kondisi ini ukuran gelembung tidak mendekati diameter pipa, tetapi diperkirakan mempunyai ukuran yang sama (uniform).

Adapun manfaat dari pengukuran kecepatan kantung udara ini adalah akan mengetahui bagaimana fenomena ke kantung udara (slug flow),

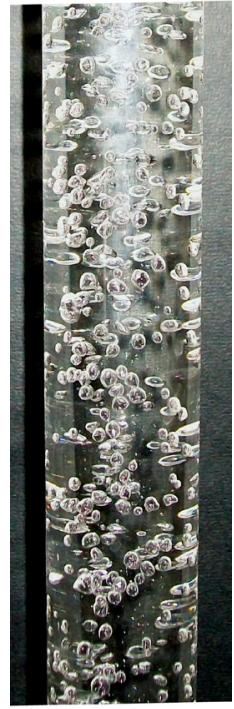

(a)

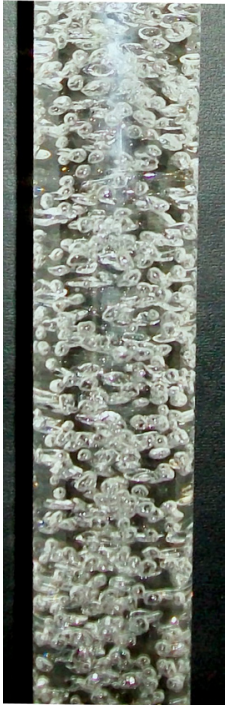

(b)

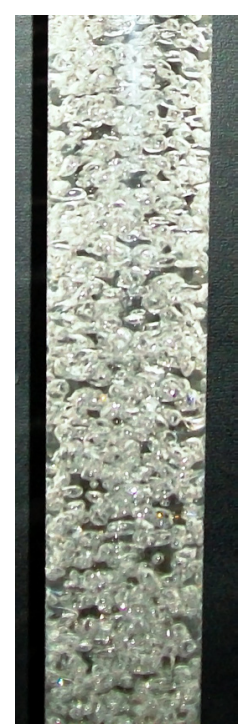

(c)
$\operatorname{Re}_{\mathrm{SL}}=49488, \beta=0,05 \quad \operatorname{Re}_{\mathrm{SL}}=49488, \beta=0,11 \quad \operatorname{Re}_{\mathrm{SL}}=49488, \beta=0,2$

Gambar 6. Visualisasi dari bubbly flow pada pipa uji vertikal dengan ketinggian $0,35 \mathrm{~m}$ di atas bubble injector untuk $\mathrm{Re}_{\mathrm{SL}}=49488\left(\mathrm{U}_{\mathrm{SL}}=\right.$ $1,1 \mathrm{~m} / \mathrm{s}$ )

apabila kantung udara yang dihasilkan lebih panjang maka semakin banyak cairan yang akan tertekan dalam lapisan di sekitar kantung udara sehingga lapisan film yang terbentuk akan semakin tipis. Sebagai contoh apabila hal ini terjadi pada peristiwa evaporasi, lapisan film yang tipis akan menyebabkan melepuhnya pipa.

Pada aliran dua fase (gas-cair) dalam pipa, akan diperoleh aliran kantung udara dan pola aliran lainnya pada kecepatan superfisial gas dan cairan yang bermacam-macam. Struktur model aliran kantung udara sangat kompleks. Aliran kantung udara ditandai oleh bentuk gelembung gas yang relatif berukuran besar dan hampir memenuhi penampang saluran aliran. Terjadinya aliran kantung udara apabila kecepatan aliran gas dan cairan terus ditingkatkan. Aliran kantung udara terbentuk pada waktu aliran kantung udara dan gelembung besar bergerak dengan kecepatan konstan kearah sumbu pipa tanpa berhenti. Kemudian gelembung kecil di pusat aliran bergerak dengan kecepatan yang sama seperti gelembung besar. Perbedaan utama antara gelembung memanjang dan aliran kantung udara adalah dalam aliran kantung udara menyebar gelembung-gelembung udara dan ditampung ke dalam kantung udara.

Sifat aliran kantung udara dapat diprediksi apabila dapat digambarkan dinamika yang terjadi pada suatu gelembung. Dalam analisa ini ditinjau satu sel atau bagian yang terdiri dari satu gelembung. Kecepatan kantung udara diperoleh dari pengukuran terhadap variabel waktu dengan jarak pengukuran 
yang telah ditetapkan. Untuk kecepatan superficial gas dan cairan lebih kecil dari $4 \mathrm{~m} / \mathrm{s}$ hasil pengukuran kecepatan kantung udara sesuai dengan persamaan Nikline, apabila lebih besar dari $4 \mathrm{~m} / \mathrm{s}$ hasilnya jauh berbeda karena alirannya bukan lagi aliran kantung.

Dalam penelitian ini untuk semua kondisi aliran pada pipa vertikal bentuknya adalah bubbly flow. Karakteristik Flow pattern bubbly flow pada pipa uji vertikal untuk setiap kondisi aliran. Menurut estimasi visual, bubbles yang dihasilkan dari injektor mempunyai diameter sekitar $3 \mathrm{~mm}$. Pengamatan menunjukkan bahwa bubbles yang terbentuk berbentuk ellips daripada bentuk bola yang bulat. Hal ini dikarenakan viskositas yang rendah dari fase cairan. Beberapa tipikal visualisasi dari bubbly flow pada pipa uji vertikal ditunjukkan dalam gambar 2-6.

Untuk kondisi aliran bubbly flow dari $\beta=0,05$, $\beta=0,11, \beta=0,2$ dapat dibandingkan untuk setiap kecepatan superficial cairan kecuali untuk $\operatorname{Re}_{\mathrm{SL}}=$ 13497, 22494. Hal ini karena keterbatasan alat ukur yaitu rotameter yang tidak dapat membaca pada kecepatan gas sangat kecil.

Dari hasil visualisasi diperoleh karakterisitik flow pattern yang berupa bubbly flow yang dapat diklasifikasikan dalam beberapa grup, yaitu:

\section{Clustered bubbly flow}

Untuk jenis aliran ini terjadi pada kecepatan superficial cairan yang tinggi dengan kualitas volumetrik gas yang rendah seperti yang ditunjukkan pada gambar 5(a) dan 6 (a). Fase gas (bubbles) yang terbentuk berkelompok cairan yang medium pada beberapa tempat di radial cross-section dari pipa. Dengan kata lain distribusi bubble tidak simetris pada sumbu vertikal dari pipa pada beberapa ketinggian dan bubble clusters terkonsentrasi pada beberapa lokasi.

\section{Homogeneous bubbly flow}

Untuk jenis aliran ini terjadi pada setiap kecepatan superficial cairan dengan kualitas volumetrik gas yang medium seperti yang ditunjukkan pada gambar 2(a), 3(b), 4(b), 5(b), 6(b). Jumlah dari bubbles menjadi lebih banyak dan bubbles yang terbentuk uniform sepanjang radial cross-section dari pipa pada beberapa ketinggian. Dan juga terlihat ukuran bubble menjadi lebih besar.

\section{Dense bubbly flow}

Pada jenis aliran ini terjadi pada setiap kecepatan superficial cairan dengan kualitas volumetrik gas yang tinggi seperti yang ditunjukkan pada gambar 2(b), 3(c), 4(c), 5(c), 6(c). Seluruh area yang melintang dari pipa dipenuhi bubbles, tetapi belum terbentuk koalisi dari bubble-bubble yang disebut elongated bubbles.

\section{SIMPULAN}

Karakteristik flow paytern aliran dua fase gascairan melewati pipa vertikal secara eksperimen untuk kondisi aliran dengan variasi kecepatan superficial cairan dari $0.3-1.1 \mathrm{~m} / \mathrm{s}$ dan kualitas volumetrik gas antara 0.05-0.2 untuk kualitas volumetrik gas rendah dengan kecepatan superficial cairan yang tinggi terjadi cluster bubbly flow, sedangkan pada setiap kecepatan superficial cairan untuk kualitas volumetrik gas menengah (medium) terjadi homogeneous bubbly flow dan dense bubbly flow untuk kisaran kualitas volumetrik gas yang tinggi. Hasil estimasi secara visual gelembung udara (bubble) yang dihasilkan dari injektor mempunyai diameter rata-rata $\pm 3 \mathrm{~mm}$. Pengamatan menunjukkan bahwa gelembung udara (bubble) bentuknya tidak bulat seperti bola tetapi berbentuk wobbling ellipsoidal. Hal ini mungkin karena rendahnya viskositas dari fase cairan.

\section{DAFTAR PUSTAKA}

Benard E., 2006. Gas-Liquid Two Phase Flow through a Vertical $90^{\circ}$ Elbow Bend, Experimental Thermal and Fluid Science 31. hal. 761-769.

Boyun Guo., 2005. Offshore Pipelines. University of Louisiana at Lafayette

Chan Y. Ching., 2007.Development of Two-Phase Flow Downstream of a Horizontal Sudden Expansion. International Journal of Heat and Fluid Flow 29. hal. 194-206.

Chi-Chung Wang, 2002. Influence of Horizontal Return Bend on the Two-Phase Flow Pattern in Small Diameter Tubes. Experimental Thermal and Fluid Science 28, hal. 145-152.

Karayiannis T.G, 2006. The Effect of Tube Diameter on Vertical Two-Phase Flow Regimes in Small Tubes. International Journal of Heat and Mass Transfer 49. hal. 4220-4230.

Kawaji M, 2002. Investigation of Two-Phase Flow Pattern, Void Fraction and Pressure Drop in a Micro Channel. International Journal of Multiphase Flow 28. hal. 1411-1435.

Seungjin Kim, 2007. Geometric Effects of 90-degree Elbow in the Development of Interfacial Structures in Horizontal Bubbly Flow. Nuclear Engineering and Design 237.hal. 2105-2113.

Seungjin Kim, 2008. Two Phase Minor Loss In Horizontal Bubbly Flow With Elbows: $45^{\circ}$ And $90^{\circ}$ Elbows. Nuclear Engineering and Design xxx, NED-5167, No. 6. 
Sira Saisorn, 2007. Flow pattern, void fraction and pressure drop of two-phase air-water flow in a horizontal circular micro-channel. Experimental Thermal and Fluid Science 32. hal. 748-760.

Speeding PL., 1998. Vertical Two Phase: Pressure Drop. Institution of Chemical Engineers Trans IchemE, Vol 76, Part A.

Somchai Wongwises, 2005. Flow pattern, pressure drop and void fraction of two-phase gas-liquid flow in an inclined narrow annular channel. Experimental Thermal and Fluid Science 30. hal. 345-354.

Taylor dan Francis, 2006. Multiphase Flow Handbook.

Tekna, 2005. Handbook of Multiphase Flow Metering. www.tekna.no.

Triyogi Yuwono, 2005.Pengukuran global void fraction pada plane poisuille bubbly flow dengan metode gradien tekanan. jurnal Iptek ITS. Vol.6, No 2, hal. 169-175. 